\section{Fraud versus carelessness}

SIR-Stewart and Feder ${ }^{1}$ protest a little too much, thereby detracting from the valuable comments they make.

Mistakes have often been made and will continue to be made, even by the eminent. To quote Heilbron": "Sometimes, to be sure, Rutherford's semi-quantitative results misled, as in the conclusion, supported by a 20 per cent error, that positive and negative ions in a gas drift at about the same velocity". They only detract from the credibility of the author and, if repeated too often, will simply "be ignored rather than deliberately gainsaid"3. As scientists are held to engage in a quest for credibility ${ }^{4}$, this may itself be penalty enough. Do mistakes add up to fraud? How easy is it anyway to fabricate data?

I recently participated in a graduate course in pharmacology in which students were required to make several oral presentations. I asked them to imagine that they were promoting a novel compound for the management of rheumatoid arthritis in a country that had suddenly opened its doors to Western medical technology, taking as their starting point existing information on anti-inflammatory drugs, gold compounds, immunosuppressants and so on. They were told their compound should purport to be an improvement on existing drugs. The students performed brilliantly. They concocted variations on existing chemical structures, gave attractive names to their compounds, provided pharmacological and toxicological profiles, devised double-blind randomized clinical trials with appropriate criteria for selection of patients and assessment procedures and cleverly interpolated their wholly fictitious data into existing information. As an observer, I was impressed with their performance and utterly shocked by how real it all seemed. They could well be reviewing published information or could have even sent their data in. It all seemed so facile. The point to ponder is not that fraud occurs, but that it appears to be so uncommon - at least till now.

But will the frequency of fraudulent publications increase? This is the rub. Will carelessness, repetitive publications and gamesmanship lead cynically to fraud? Do these form a continuum? It is particularly disturbing that in recent years the highly publicized accounts of fraudulent work have been linked to scientists in the biomedical disciplines, particularly in North America.

The explosive growth of the biomedical community has come at a price. Universities have allowed unbridled growth of their medical schools, as medical faculties attract funds, often generate their own salaries and plough money back into the universities. The young clinician-scientist is forced to juggle his time between seeing patients, generating his salary, administering his unit, teaching students and doing research. Because of ceilings on incomes, clinicians attached to medica schools often earn far less than their peers in practice and thus make considerable financial sacrifices to pursue their careers. The powers-that-be who indulge in gratuitous quantification force them to publish more than they should.

In all this, senior clinician-scientists are squarely to blame. They cannot take refuge in describing fraud as aberrant behaviour, as Braunwald has done, for they create the environment that makes fraud possible. Macklem ${ }^{5}$ noted that "the cutthroat and poisoned atmosphere that results is hardly conducive to originality and creativity". They exercise considerable influence on granting agencies, sit on tenure and promotion committees and often become role-models to be emulated. In fact, many are; I have personally been privileged to work under several. A simple message that excessive publications will be penalized will be easily understood. Senior scientists (particularly in clinical disciplines) can do far better for their junior colleagues by protecting their research time and cautioning them that incessant brownian motion does not necessarily equate with progress. Frankly, it is not too difficult to be productive in a quantitative sense - it merely requires a certain lack of imagination and a willingness to get bored and be boring. About 20 years ago, Ziman wrote of those who "rush into print with the notebooks of the previous day's experiment" (intellectual fraud?). It is only one small step then to rush into print with non-existent notebooks of never-done experiments.

Department of Medicine,

P.K. RANGACHARI

Intestinal Disease Research Unit,

McMaster University,

1200 Main Street West,

Hamilton,

Ontario L8N 3ZS, Canada

1. Stewart, W.W. \& Feder. N. Nature 325, 207-214 (1987).

. Heilbron, J.L. in Rutherford and Physics at the Turn of the Century (eds Bunge, M. \& Shea, W.R.) (1979)

Ziman, J.M. Public Knowledge, p. 115 (Cambridge University Press, 1968).

4. Latour, B., Woolger, B. in Science in Context (ed. Barnes, B. \& Edge, D.), 35-43 (Open University Press, Milton B. $\&$.

Keynes, 1982

5. Macklem, P.T. Clin. Invest. Med. 8, 85-88 (1985)

SIR-In your issue of 15 January 1987, your leading article and Commentaries by W. W. Stewart and N. Feder and E. Braunwald deal with a scientific fraud, which the whole community would agree was reprehensible. However, other practices occur much more widely, but they are rarely admitted. Among these, some scientists:

(1) do not attempt to publish results of their own or their team's experiments that contradict their own hypotheses;

(2) do not carry out crucial control experiments, which they have no reason to believe have already been published, or to which their attention has been drawn;

(3) pay lip service to the known limitations, artefacts and assumptions inherent in the techniques they have employed, but do not take them into account when drawing conclusions or making calculations in respect of their experiments;

(4) accept or demand co-authorship of publications - thereby assuming equal intellectual responsibility for publications resulting from experiments - to which they have given little or no supervision and in which they have hardly participated physically;

(5) omit from publications important details of experiments that would be necessary to make them repeatable;

(6) do not cite publications reporting experiments or observations that predate or contradict their own;

(7) as referees, give insufficient attention to papers in relation to the time and resources the authors have employed, and then hide behind their anonymity when criticized;

(8) as referees, recommend the rejection for publication of manuscripts presenting views or findings that they do not like;

(9) as referees, recommend the rejection for publication of manuscripts whose conclusions they feel are wrong, but in which they cannot identify the mistakes;

(10) as organizers of conferences, seminars and symposia, prevent the presentation of views, however well argued, that they consider 'heretical', 'controversial' or 'unorthodox';

(11) are unwilling to discuss their own research work or fundamental aspects of their own work or discipline, privately, publicly or by correspondence;

(12) influence committees to reject applications for grants likely to produce results they would not like, or by research workers of whom they disapprove.

I believe that the scientific community is far too tolerant of such practices, often dismissing evidence for them by pointing out that research workers are as human as the rest of the population. I believe that the combined impact of the above practices upon the corpus of knowledge is far greater than the rare and unpopular acts of fraud.

Unity Laboratory of Applied

H. Hillman

Neurobiology,

University of Surrey,

Guildford,

Surrey GU2 5XH, UK

Letters submitted for Corresondence should be typed, double-spaced, on one side of the paper only. 